\title{
A Bourdieusian Analysis of the Sociocultural Capital of Chinese International Graduate Students in the United States
}

\author{
Xinxin Wang \\ Rebekah Freed \\ University of North Carolina at Chapel Hill, USA
}

\begin{abstract}
For the last decade, Chinese international graduate students (CIGS) have represented the largest portion of international graduate students in the United States. Previous research studies on language barriers and cultural differences have revealed that CIGS experience difficulties in adapting to the American educational system (Zhang-Wu, 2018). Few researchers have critically examined the experiences of CIGS on a more organizational level. In this qualitative study, we analyzed interviews with CIGS utilizing a Bourdieusian (1986a) framework to identify the social and cultural capital (SCC) that CIGS possessed. We argue that SCC concepts can help theoretically and critically examine the experiences of international students as a minority student group in the United States. The results from our in-depth semistructured interviews imply that CIGS are excluded from access to and possession of the SCC necessary to adapt to academic, cultural, and social life in the United States.
\end{abstract}

Keywords: Chinese international graduate students, cultural capital, social capital, higher education, international education

\section{INTRODUCTION}

When international students attend higher education institutions in the United States, it benefits both the international students, as well as the American universities and the broader economy and society. The increase of international 
student enrollment in U.S. universities has had a significant positive economic impact for the United States. During the 2018-2019 academic year, the 1,095,299 international students studying at U.S. colleges and universities contributed around $\$ 45$ billion to the U.S. economy. Additionally, international students either created or supported 458,290 jobs in the United States, which benefits the U.S. economy and the job market (National Association of Foreign Student Advisers, 2019). International students also contribute to America's scientific and technical research and bring international and cultural perspectives into U.S. classrooms. International students interact with and influence fellow students at U.S. universities and therefore help prepare American undergraduates for global careers through exposure. International students building friendships and relationships in the United States can lead to long-term business relationships and subsequent economic benefits (Institute of International Education, 2018).

The enrollment of international students has been increasing in American universities, including undergraduate students, graduate students, students with optional practical training, and nondegree students for the past decade. China has been one of the top countries of origin for international students in the United States in recent decades. There are 369,548 Chinese international students currently enrolled in universities in the United States, and more than one third $(133,396)$ are Chinese international graduate students (CIGS; Institute of International Education, 2019). International students benefit from studying abroad because it provides an opportunity to expand their career choices. Many Chinese international students believe that the more merit-based system in the United States is fairer in terms of admission, graduation, and job attainment and will therefore better position graduates to achieve their personal goals. Students' decisions about going abroad are also influenced by their friends or relatives who have already gone abroad (Cao, 1997). Another emerging factor that propels Chinese students to study abroad is social and peer pressure.

Despite Chinese students representing such a large portion of the international student body, they face many obstacles when studying in a foreign country. While they are willing to engage in the difficult journey of leaving their home country and traveling to the United States to pursue higher education, they must also navigate a complex visa process, master a foreign language, adjust to unfamiliar cultural norms, and deal with discrimination, all for the benefit of an education from quality U.S. universities (Gold, 2016; Lee \& Rice, 2007). A majority of studies on Chinese international students focus on those individual factors and tend to overblame the international students themselves for adjustment and well-being problems in their host countries (Zhang \& Goodson, 2011). Few researchers have explored stressors and inequality from the environmental factors (e.g., American professors, peers, and universities) that critically influence international students' experiences. To fill the literature gap and to provide more insights on practical solutions on how to better support Chinese international students, we use Bourdieu's (1986a) concept of capital as a critical lens through which to study the access to and possession of resources and support for Chinese international graduate students (CIGS) in their academic and social lives in the United States. 


\section{LITERATURE REVIEW}

International students play an important role in U.S. higher education. However, they may encounter a disparity between their social and educational aspirations and their narrowly defined status as a fee-paying "alien" (Habu, 2000). These challenges often impact international students' lives in complex and intersecting ways. In Kuo's (2011) study of 152 international graduate students' experiences at a Southern university in the United States, the language challenges that international graduate students face in the southern United States were intertwined with cultural challenges due to differences in culture and background. Lin and Scherz (2014) found that Asian international graduate students face similar challenges in the United States. Asian international students, especially Chinese international students, experienced higher levels of stress and discrimination than their European international peers due to larger cultural distance in communication and education between their home and host countries and lower English language proficiency (Alharbi \& Smith, 2018). Zhang-Wu (2018) conducted a critical literature review of 21 peer-reviewed articles on Chinese international students since 2000 and found that all publications focused on individual experiences in three aspects: language barriers, acculturation, and intercultural communication. Very few researchers have studied how Chinese international students are supported through organizational, regional, or national efforts. One exception is that Cho and $\mathrm{Yu}$ (2015) studied university support for international students at a university in the southeastern United States through surveying 131 international students from 33 countries. They found that university support and students' perceived support is influential in students' wellbeing, including psychological stress and school-life satisfaction. Additionally, Zhang$\mathrm{Wu}(2018)$ noted that few articles employed a critical stance when empirically studying the issues that Chinese international students encounter, typically attributing their negative experiences to cultural differences and failing to highlight issues of race and racism, which are more systemic in institutions.

Distinguishing graduate students from the body of literature on Chinese international students is necessary for our study because CIGS may possess more established Chinese worldviews, values, and habits compared with younger Chinese international undergraduates, so CIGS may experience different challenges or support. Some researchers have begun to study cultural stereotyping and negative labeling experienced by female CIGS in Canada (Ge et al., 2019). In order to deepen the understanding of how CIGS overcome stressors and learn to adapt in U.S. graduate schools, we identified two central research questions:

1. Does the capital that CIGS possess or lack help or hinder their adaptation to the American education system?

2. How does the capital function during the adaptation process of CIGS? 


\section{THEORETICAL FRAMEWORK}

Pierre Bourdieu's work reveals the contradiction between democratic goals and reforms and how they fail to close achievement gaps and eliminate social inequality (English \& Bolton, 2016). Bourdieu (1986b) suggested a relational approach to studying education by introducing three key concepts to explain how this mechanism works: habitus, field, and capital. Habitus can be understood as an individual's life expectations and dispositions shaped by that individual's life space. Habitus is framed by our past and upbringing, but also shapes our future (Bourdieu, 1984). Bourdieu emphasized structure as part of habitus to show that habitus is not random, because it has predictable patterns "inscribed in our bodies, in things, in situations, and everyday lives" (Bourdieu, 1991, p. 51). School systems, for example, are crucial in enhancing existing habitus and in building new habitus. School systems also provide a structure that accepts the dominant social rules. Therefore, it is clear that some groups favor the school's habitus while other groups experience it as confusing, segregating, and contentious (English \& Bolton, 2016).

Field is another key concept in Bourdieu's sociology. The term "field" refers to different social "spaces," networks, or configurations imposed by specific values and rules (Bourdieu, 1990). International students are positioned in intersected fields, or different institutional spaces, and are positioned in different policy and regulation fields related to their academic status in the United States (Tran, 2014). Bourdieu also argued that social groups should be classified by people who live in a similar habitus with shared experiences and beliefs. Agents or players within in a field accept the "rules of the game" governing their activities, though the "rules" are often learned unconsciously (Bourdieu, 1986a). For example, social fields exist between Asian students, as well as among Asian students and Americans.

\section{Economic Capital, Social Capital, Cultural Capital}

Bourdieu contributed his theoretical applications to the sociological studies to education, including extending the concept of capital. Economic capital refers to a form of capital "which is immediately and directly convertible into money and may be institutionalized in the form of property rights" (Bourdieu, 1986a, p. 15). Research funding, for example, is important economic capital for CIGS. Bourdieu extended the concept of capital beyond its economic realm to include nonmaterial aspects of capital (i.e., social and cultural capital [SCC]; Bourdieu, 1986). These immaterial aspects of capital are considered sources of capital because they can be transferred to economic capital (see Figure 1). 

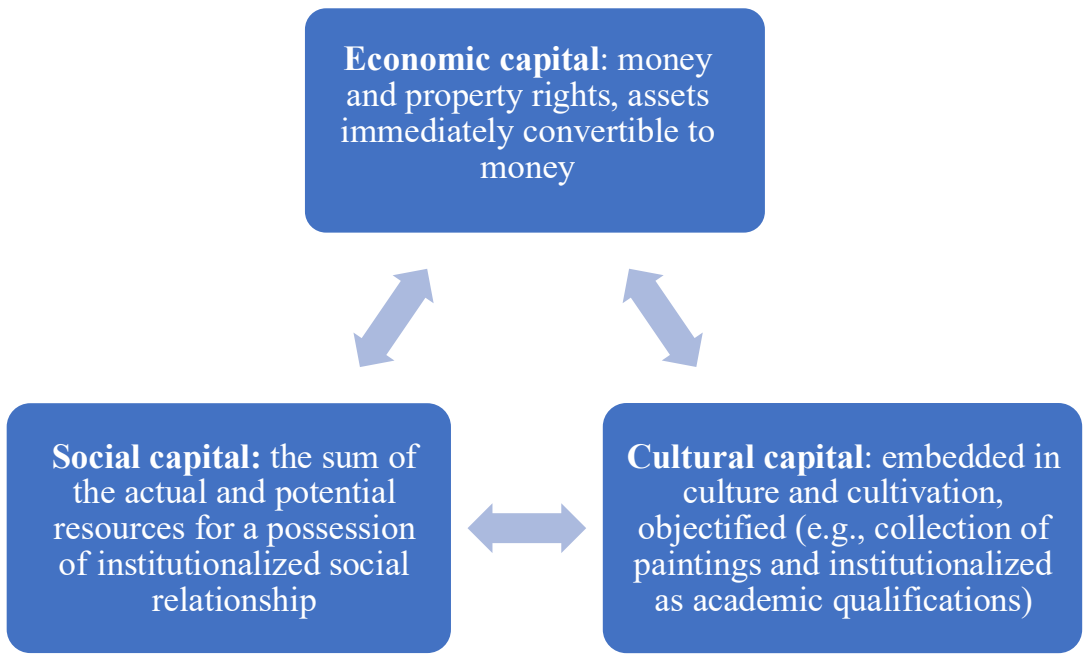

\section{Figure 1: Conversions of Material and Nonmaterial Capitals}

Bourdieu (1986a) described social capital as:

...the aggregate of the actual or potential resources which are linked to possession of a durable network of more or less institutionalized relationships of mutual acquaintance and recognition - or, in other words, to membership in a group - which provides each of its members with the backing of the collectively owned capital. (p. 21)

Social capital can be considered the ability of the social fields or networks to create or foster capital. Being at the intersection of different fields or networks can mean both unique difficulties, as well as unique possibilities, for CIGS.

Bourdieu (1977) also described cultural capital, which is all of the "instruments for the appropriation of symbolic wealth socially designated as worthy of being sought and possessed" (p. 488). Cultural capital presents itself in three states: an embodied state, an objectified state, and an institutionalized state. Bourdieu (1986a) expressed that an embodied state occurs when one has accumulated cultural capital unconsciously via culture and cultivation (p. 18). Acquiring cultural capital via an embodied state results in "the form of longlasting dispositions of the mind and body" (Bourdieu, 1986a, p. 17). Material goods and media represent cultural capital in an objectified state (Bourdieu, 1986a, p. 19). For example, a collection of paintings (objectified cultural capital) can be converted to economic capital by sale. Cultural capital in an institutionalized state (Bourdieu, 1986a, p. 20) generally refers to academic qualifications (e.g., a teaching certificate). Cultural capital is invisible and can be overlooked when considering educational investment and gains. As the individual embodies capital, it becomes a type of habitus (i.e., the embodiment of cultural capital; Abbas, 2004, p. 16). 
Bourdieu's concept of capital has been widely applied to educational research (Davies \& Rizk, 2017; Dika \& Singh, 2002), particularly on schooling and the inequalities that students who are racial and ethnic minorities experience (Abbas, 2004; Stanton-Salazar, 1997; Warikoo \& Carter, 2009). Research has shown that possessing capital contributes to students' sense of belonging and resilience to schools (Glass \& Gesing, 2018). Researchers also frequently show that there is a direct correlation between students' access to and possession of SCC and their educational attainment and achievement outcomes (Bernstein, 2000; Lareau, 2003; Lareau \& Horvat, 1999). Stanton-Salazar (1997), in his widely adopted theoretical paper on social capital framework, linked social capital to the racial inequities that minority groups experience, describing how social capital can be leveraged to economic capital through means accessible to those included in a social network or field, and withheld from those who are systemically not included in social fields.

We found Bourdieu's concepts of habitus, field, and capital useful in attempting to understand the CIGS' adaptation into U.S. higher education. International students as a unique ethnic minority group are surprisingly overlooked in racial and educational research. The U.S. educational setting can be considered a social field with its own rules, shared experiences, and beliefs. However, studying CIGS complicates the research, because CIGS are placed in two different social fields: Chinese and American. The concept of habitus is relevant for understanding the structure of dynamic life patterns of CIGS when they move to a new social space (i.e., field) in the United States. In the context of studying Asian international students, Abbas (2004) stated that the social capital concept "elaborates the importance of networks, associations and "connections"" (p. 27). Abbas (2004) argued that the concept of cultural capital is useful because it "considers the micro-process at work, as pupils engage with parents, teachers and the system itself" (p. 27). The SCC framework has yet to be applied to study CIGS in the United States, though some scholars have utilized the SCC framework to study Chinese students in China (Liu \& Brown, 2014; Sheng, 2012). Following the line of research by Abbas (2004), we argue that the SCC framework is more microoriented for categorizing aspects of cultures and social networks, which will then help reveal how CIGS in our study adapt to and navigate U.S. institutions of higher education, as well as if and how these institutions support them during this process.

\section{METHOD}

We focused on the interpretation (Lincoln \& Guba, 1985) of graduate lives of CIGS and looked for richness in context and narratives to answer the research questions. As such, we decided that a qualitative study was the appropriate research method (Levitt et al., 2018). Furthermore, we applied a multiple-case study (Yin, 2017) analysis on 10 Chinese students. We developed the interview protocol (see Appendix A) guided by the SCC framework and conducted two pilot interviews with two CIGS to revise the interview questions. The first author, as a Chinese graduate student herself, has studied CIGS in the United States from 
sociological and cultural perspectives for years, so she has a general understanding of the literature and experiences of CIGS. Since she came into the study with ideas about what she wanted to learn, she chose to conduct semistructured interviews, which would provide some flexibility and the possibility of open discussions.

\section{Participants}

The sample was chosen according to the convenience of the first author, who is a doctoral student at a southeastern American university and has many personal contacts with CIGS. The targeted research participants in this study were current or recent graduate students (i.e., students who graduated within 5 years) from China who studied in the United States. The first author used snowball sampling (Marshall \& Rossman, 2016) and interviewed participants starting with direct contacts and expanding outward to participants with less direct connection to the first author. The first author began interviewing friends who are current or recently graduated CIGS, and then participants recommended others to enlarge the sample size. Participants were purposefully sampled to include meaningful and various perspectives for the study (Marshall \& Rossman, 2016). The 10 interviewees attended eight different U.S. higher education institutions located in the northeastern, southeastern, and middle United States.

\section{Data Collection and Analysis}

Each interview was designed to last $45 \mathrm{~min}$, although most interviews took longer than expected, because the participants were eager to share their experiences. Overall, the interviews ranged from 36-128 min, with six interviews lasting more than $1 \mathrm{hr}$ each. For participants who lived remotely, the first author scheduled a video chat or phone call to conduct the interview. All names presented in this article are pseudonyms. Running notes and reflection notes were utilized as part of the interview process and for data analysis (Marshall \& Grossman, 2016). Appendix B shows interviewee details including gender, major, interview length, location of interviewees, current student status, and mode of interview. All interviews were completed within one month. The first nine participants chose to conduct the interview in Chinese, and the last participant chose English for the interview. All the interviews were audio-recorded for further analysis. The first author translated all Chinese audio interview records to English for constant comparative coding and thematic analysis and to interpret the interview results (Saldaña, 2009). The first author developed codes based on the capital framework and generated new codes if new topics arose from interviews, and then she summarized the codes into themes for future analysis. The second author worked with the first author to provide an impartial view on general methodology and research findings (known as peer debriefing) (Marshall \& Rossman, 2016). When the two authors had different interpretations during the coding and data analysis process, we critically examined and communicated our perspectives as 
researchers and graduate students from different cultures and habitus to reach an agreement.

\section{Positionality}

The first author is a Chinese international graduate student in the United States. Her shift from being a member of a majority group in China to a minority group through studying abroad further challenged her life in the United States. She is from the Han ethnicity, which makes up $92 \%$ of the population in China. Therefore, she never expected to experience how being a minority complicates everything in life. She experienced extensive stress in adapting to academic and social life in the United States, and she started wondering whether other Chinese students experienced similar problems. The second author is an ethnically Jewish, White female who was raised in Southern California. She lived in areas and attended multicultural schools with a majority of Asian-American students. When she moved to other parts of America to teach, she saw how minority populations were marginalized in predominantly White spaces, and became interested in supporting students from diverse backgrounds. She contributed her knowledge and skills in qualitative methodology and writing, and worked with the first author to validate the coding and themes.

\section{RESULTS}

Through the 10 interviews, we found that a combination of language, cultural, social, institutional, and personal factors influenced the academic and social experiences of CIGS. We will discuss factors of adaptation in terms of habitus and cultural capital (particularly embodied cultural capital), sources and benefits of SCC, and disadvantages regarding the lack of access to or possession of capital. We will analyze the stressors and difficulties of CIGS through a Bourdieusian lens, which we will follow with an in-depth discussion of CIGS' experiences in U.S. graduate schools.

\section{Changing Habitus}

Unpreparedness emerged as a theme in the interview data in three distinct ways. First, CIGS were not prepared to move to the United States for graduate school when they lived in China before beginning graduate school. Second, CIGS were not prepared for the job market after graduation. Third, American educators seemed unprepared to teach CIGS.

Participants expressed that in China, English learning is focused on writing and reading. The most common class format in China is a lecture format with little student participation due to large class sizes and intensive class agendas. Our participants received minimum language training in school and had minimal contact with native English speakers in China before moving to the United States. Additionally, many participants reflected that they did not have a clear career plan when they came to America, even after they received admission offers from 
American schools. Kan reported that he didn't do enough research on his first doctoral program to gain sufficient experience, so he found a big mismatch between his interests and his research teams. Kan reapplied to and enrolled in another doctoral program after 2 years at his first program. The participants reported that such unpreparedness created a lot of confusion and stress.

Coming to the United States from China is a huge change of habitus in educational background, family experiences, and social interactions (English \& Bolton, 2014). CIGS are faced with struggles while accumulating new elements of capital in America. Tran (2016) argued that if there is a harmony between international students' habitus and the institutional environment of the host country, students would adapt into the new environment as "fish in water"; if there is a mismatch between the two habitus, students often have difficulty understanding the rules of the game. Our findings corroborate this.

Participants also expressed that American professors seemed underprepared to teach CIGS in their classes. $\mathrm{Li}$ and $\mathrm{Wu}$ shared that their professors had very little knowledge about Chinese education and did not indicate any willingness to learn more about China's education in order to help their students' transition. Li and Wu felt that the professors' lack of awareness about CIGS made them more academically isolated in class discussions and as they developed their respective research directions. Li felt that knowledge of culturally responsive pedagogical techniques (Gay, 2010) would help American educators to better address CIGS' needs and interests in the classroom. Li said,

They [professors] listen to me politely and nod occasionally, but I can tell they are not quite interested when I am talking about education in China. I am not angry or disappointed though, it is just like, I feel sorry for them. It is their loss, not mine. Sometimes there are many things worth learning from China's math education.

It is difficult for both CIGS and American educators to discern that their predispositions and unpreparedness are bounded by their respective habitus, which is often unconscious. Introducing the concept of habitus into analysis makes it easier to recognize the educational inequality that CIGS experience in the American system due to the general unpreparedness of the system and individuals to handle them. Brantlinger (2003) commented on the inequality in schooling, saying,

Given the prevalence of school hierarchies and their resistance to change, it is reasonable to hypothesize that existing structure and practices are durable precisely because they correspond to influential people's desires, hence from their power to create and retain them. (p. 2)

As newcomers to America, CIGS have difficulties in interpreting the existing hierarchies that influence their life, while American educators' resistance to accommodating for the habitus change of their students contributes to an unequal environment for CIGS. 


\section{Embodied Cultural Capital Accumulated in China}

All participants expressed a huge gap between Eastern and estern cultures. Participants discussed elements of culture relevant to their experiences as being "language and talking patterns," "thinking patterns," "cultural taboos," "common values and beliefs that people share," "food culture," "lifestyle," and "knowing how to reach a certain group of people." The last aspect reflects the idea of social networking. Participants agreed that understanding American culture is the first step for building a useful social network for studying and finding a job in the United States.

$\mathrm{Li}$ and $\mathrm{Wu}$ emphasized the speaking culture they experienced in and outside of American classrooms. Wu said she learned to speak up in class, and as a result has obtained appreciation from several professors, who in turn helped her secure funding and be more successful in academic learning. Wu's experience shows how CIGS sometimes report accumulating mainstream sociocultural capital (i.e., SCC) and converting it into economic capital (i.e., funding) and social capital (i.e., social networks). Li talked about different speaking cultures between the United States and China:

Have your voice, speak out. This is what Americans prefer. Chinese prefer to be silent, to be humble, then opportunities are seized by others. Students' requests will be taken up by a higher level of administration [at school], if not solved at a lower level. I think in this case American schools are doing a good job in listening to students and student services. Chinese students have a weaker sense of protecting their rights. Chinese are more complicated. They have different ideas in mind while they don't speak out. It is hard to guess what Chinese think.

Chinese students studying in the United States have moved away from their familiar social settings in which they developed their embodied cultural capital and predispositions (habitus) framed in China to a new social field (Bourdieu, 1990). Language, as an aspect of embodied cultural capital, is influential to their adaptation, but established structures and shared values in the new educational system have more impact. Most participants said that their first year in the United States was the most challenging, but they found that the language barrier diminished after their first year of stay.

One recurring pattern we found was that participants expressed reluctance about talking in class, especially with the extensive class discussions and group work they found in the U.S. classrooms. Some participants expressed that due to the cultural difference regarding expectations for speaking in class, CIGS sometimes feel invisible. According to the literature, two factors can explain CIGS' unwillingness to speak in class. First, students in China are typically taught to be humble in speaking. In Chinese culture, speaking out actively can be seen as wasting the public's time, and time should be allocated to each student evenly in China. The second factor is that Chinese students are taught to make sure their answers are $100 \%$ correct before speaking out, since making mistakes is a shameful behavior in Chinese culture ( $\mathrm{Li}, 2012)$. The ability to remain humble 
and silent in social settings like classrooms might have been considered a source of cultural capital in the Chinese educational system, but for our participants, this cultural value became a disadvantage when trying to adapt to American classroom culture.

\section{American Academic Advisors as the Only Source of Sociocultural Capital}

When asking about social networks, half of the interviewees mentioned their academic advisors as the major (or only) way to reach to a broader social network. Wu said:

The most satisfying thing in my doctoral study is that I have an excellent academic advisor. She shows genuine care to her advisees. She doesn't only recommend me collaboration opportunities with other scholars for publications, but also tells me the cultural norms, hidden rules, and her life stories. The latter part helps me a lot in adapting to the doctoral program, which is overall not always available to many international students.

Wu's advisor was also her primary source for learning about American culture, including academic culture and school culture. This relationship with her advisor helped $\mathrm{Wu}$ accumulate cultural capital so she could adapt into the U.S. education system. Wu's advisor also functioned as her major source of social capital, because she helped $\mathrm{Wu}$ build networks with more researchers and professors within and beyond her school. This contributed to Wu's career and scholarship development in terms of publications and job applications. Furthermore, Wu's accumulation of SCC helped her graduate with a $\mathrm{PhD}$ degree, a source of institutionalized cultural capital (Bourdieu,1986a). Wu's case demonstrates that social capital (e.g., academic networks) and cultural capital (e.g., academic degrees) can be fluid and interchangeable.

Other participants shared similar sentiments. Cong said that his advisor introduced him to a company manager, which led to his first off-campus internship in the United States. Cong further explained that it was very difficult for international students to find an off-campus internship due to unfamiliarity of the internship search process and noncitizen status. Another participant, Yuan, explained that his major field included only a small circle of people, so almost all researchers in his field know each other. Without an access to the "circle," Yuan couldn't imagine how he would have found a job without his advisor and dissertation committee. Cong and Yuan's cases serve as an example of converting social capital (i.e., social networks) to economic capital (i.e., paid salary; Bourdieu, 1986a).

Hao provided a counterexample, because her advisor was not supportive of her doctoral study. She spoke frankly that there is not much overlap between her advisor's research and her research interests. As a result, she felt that her advisor somewhat overlooked her. She reported that they met less than one time per semester. Hao felt that she received minimum guidance and mentoring from her advisor. Hao's lived experience highlights the importance of CIGS having a 
supportive academic advisor as the major source of sociocultural capital for adapting into the new habitus without unfairly bearing stress and difficulties at an unnecessary high level due to her limited access to mainstream SCC (Warikoo \& Carter, 2009).

\section{The Absence of Institutionalized Sociocultural Capital}

Many interviewees expressed that access to international career services provided specifically for international students is critical for CIGS seeking a job in the United States. Surprisingly, four participants mentioned that their programs and universities provided no international career services. Most of the interviewees reported that, due to visa limitations and different language and cultural backgrounds, the current career services provided to mainstream university students are often not useful or applicable to CIGS. One exception is Wang, who experienced some positive examples of institutional effort. Wang said professors in her master's program were responsive and actively came to students to offer references. Wang's master's program organized trips and events for international students to interact with American peers. Chee and Meng also discussed experiencing the "halo effect" of their university having a high reputation, which gave them priority in the competitive job market. However, the "halo effect" disappeared after the first year of graduation.

Participants mentioned the importance of universities having a welcoming and inclusive institutional culture on campus and in programs. Hao felt that her program was not very open in providing individual support and sharing assistantship opportunities. Hao expressed that she was not good at interpreting the competitive institutional culture, and professors and students weren't open about sharing resources and scholarship information during her first year of the $\mathrm{PhD}$ program. As a consequence, she said that she felt she often "stepped on people's toes" and caused misunderstandings with other professors or peers, which led to anxiety. It seems like Hao was limited in accumulating helpful SCC to help her understand the "rules of the game" in her program (i.e., an academic field). Bourdieu (1986b) argued that to maintain the membership in a social field and accumulate capital, members of a social field follow the "rules of the game" unconsciously. Moving from one culture to another, CIGS may be following different "rules," which may conflict with their own interests and values. Given the different habitus that CIGS were situated in before their move to another country, the absence of institutionalized SCC for CIGS serves as a clue that many experience injustice and educational inequality.

\section{Isolation and Denied Access to Sociocultural Capital: "I fight for myself all alone"}

One unique dimension of SCC that arose during the interviews is that most participants identified themselves as both the major positive force behind learning to adapt to the cultural and social system and the reason for failing to adapt to U.S. higher education. They often blamed themselves for failing to communicate well 
in English, for not participating actively in American classes, for the mental stress from thinking about and doing things differently, and for American teachers' failure to acknowledge their existence. For example, Cong said, "All of my difficulties are personal. It is due to myself not being perfect enough." Similarly, Hao expressed:

I don't think my struggles came from others. I deeply blame myself every day. I have visited my doctor for two years for my diagnosed clinical depression. Chinese people like to blame themselves for whatever difficulties they go through. I don't think self-accusation is a bad thing. Self-accusation leads to self-cultivation and growth.

Meng said, "No one and nothing has ever helped me. I am not good at social networking. I fight for myself all alone. I found my job after graduation all on my own." Kan said that personal endeavors and planning are the most important things for doctoral study.

The incredibly high level of self-blame and self-reliance has been interpreted positively by some researchers (Marginson, 2014; Tran, 2014) when studying forms of capital possessed by international students, in that international students are self-performing agents who "have the capability to pursue the course of life that they regard as being worth living" (Tran, 2014, p.2). However, the isolation and required self-reliance that participants expressed is evidence that the U.S. higher education system suffers from a systematic lack of support for CIGS navigating academic and social experiences in the United States. Future studies can provide further inquiry into the reasons CIGS experience so much isolation, because isolation may influence feelings of stress and wellbeing. These feelings may further complicate the relationship between CIGS and their programs, institutions, and educators.

\section{DISCUSSION AND CONCLUSION}

Overall, we found that there were more negative than positive comments about CIGS' experiences attending graduate school in the United States. These include differences in capital and habitus that create challenges in teaching, learning, and communicating. Our results indicate that institutional support for CIGS is also minimal. American schools and educators are demonstrably not prepared to teach CIGS, while CIGS are not prepared to enter graduate school in a different language, culture, and education system. Family members and friends seem to be too far away to help supports CIGS' social and cultural adaptation. The SCC framework helped illuminate the difficulties and coping mechanisms of CIGS in U.S. schools. As shown in Figure 2, academic advisors and the students themselves are the major sources of SCC that benefit CIGS in adapting to U.S. education. Portes (1998) recommended that researchers who study SCC should distinguish the three aspects of the social capital concept: "(a) the possessors of social capital (those making claims); (b) the sources of social capital (those agreeing to these demands); (c) the resources themselves" (p. 6). We distinguish between the sources of SCC and resources (benefits) from them in Figure 2. 


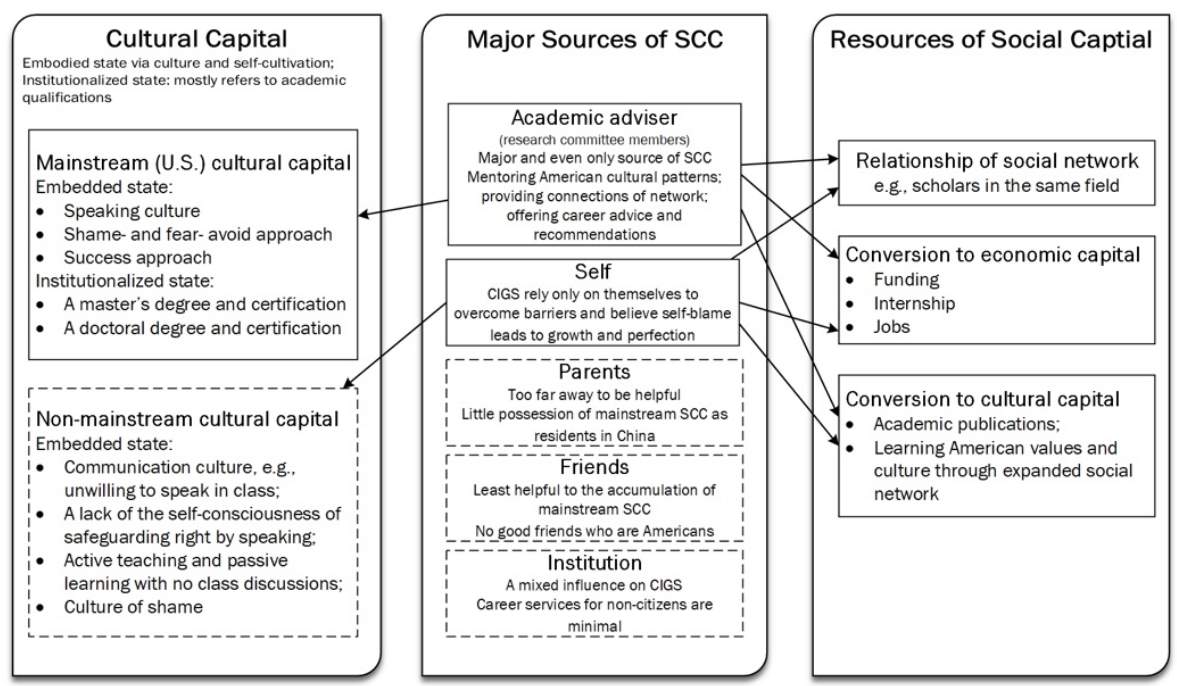

Figure 2: Taxonomy of Sources and Accumulation of SCC of CIGS

Note. The term Sources refers to the subjects that help CIGS to access more benefits; Resources refers to the benefits. Content in solid-lined boxes are positive sources and resources of CIGS in adapting to the U.S. education, while dashed boxed are negative or helpless sources and resources.

CIGS' fear of negative evaluations based on a less-developed foreign language contributed to the participants' fear of leaving a negative social impression, especially for graduate students, who are keenly aware of their social impression (MacIntyre \& Gardner, 1989). Being a part of the American speaking culture is a piece of mainstream cultural capital that CIGS do not possess. The Chinese cultural tradition of speaking indirectly and amicably $(\mathrm{Li}, 2012)$ rather than speaking to the point and directly explains the difference in SCC. A significant learning tradition in China comes from the value demonstrated in the commonly used phrase, "Actions are better than words." Whether people choose to speak or keep silent carries significant cultural meaning. It would be an interesting avenue of future research to study whether American teachers who demonstrate sensitivity to the cultural values of CIGS find more success of CIGS in assisting their acculturation process in classes.

According to SCC theory as applied to our data, mainstream SCC refers to SCC accumulated in the United States about how to find, locate, or make economic resources. Warikoo and Carter (2009) argued that even though racial minority groups have access to their own forms of capital, their nondominant capital "funds" do not help them succeed in schools in the way that the mainstream capital does for the students who possess it. Mainstream capital prioritizes students who possess this particular kind of capital in negotiating the school 
environment, which is based on American middle-class culture, values, preferences, and ways of thinking (Lareau, 2003). When the capital that CIGS accumulated in their home country is not helpful in the adaptation process and they have limited access to the mainstream capital, it can be deleterious for CIGS, as having a sense of belonging is key to educational success for all students (Strayhorn, 2012). The huge shift of academic and social habitus, as well as a shift in social spaces (field) can be sensed but is often unconscious or invisible. These invisible challenges provide additional difficulty for CIGS as they struggle to adjust. Culture is an often an invisible, pervasive element of the environment, and it complicates CIGS' already difficult task of navigating their way in the American system and higher educational contexts.

\section{Limitations}

This study has limitations in several aspects. First, there is the possibility of response bias among interviewees, because interviewees may not have been willing to share all of their issues, problems, and deep feelings. Second, the SCC framework, though widely adapted in research for social justice and equity issues of marginalized groups, includes some vague definitions. For example, there is no established way to explain the exact content of cultural capital, and researchers may confuse the difference between sources, resources, and benefits of social capital (Portes, 2014). Our study serves as a careful attempt to develop the SCC concept and articulate the difference between sources, resources, and benefits. Third, due to the small sample size and the nature of our study, we cannot generalize the problems and possessions of capital from this sample to the whole population of CIGS. However, we did not intend to extrapolate our findings, because that is not the purpose of qualitative research, which is instead intended to describe in depth answers to research aims (Levitt et al., 2018). Further research can be conducted to establish a more systematic or generalizable interpretation of SCC and CIGS.

\section{Implications}

Our study has several implications. Currently, there is no existing research on the SCC of international students in the United States. Further studies in the area of international students' SCC may contribute to a deeper connection between CIGS' experience of support or lack of support and SCC manifestations. International students have diverse backgrounds and identities, and thus are valuable subjects to future research in the field of diversity and social justice. In practice, the themes present in these data provide insights about problems in international education, and our findings reveal how CIGS experience the lack of support for international students. This line of research can enhance mutual understanding between Americans and international students and may also contribute to reforming policies in order to better support education and career services for international students. Our findings suggest that getting to know international students' cultural styles and building connections with them first 
may be a pedagogical benefit. In the field of teaching and teacher education, this article can also be used as a reference for teachers, as a case for using culturally responsive teaching practices with international students (Gay, 2010). Further research conducted on supporting CIGS at different levels in institutions of higher education would greatly benefit students and universities alike.

Note

Appendices for this article can be found on the JIS website at https://www.ojed.org/index.php/jis

\section{REFERENCES}

Abbas, T. (2004). The education of British South Asians: Ethnicity, capital and class structure. Palgrave Macmillan.

Alharbi, E. S., \& Smith, A. P. (2018). Review of the literature on stress and wellbeing of international students in English-speaking countries. International Education Studies, 11(6), 22-44. https://doi.org/10.5539/ies.v11n6p22

Bernstein, B. (2000). Pedagogy, symbolic control and identity, theory research, critique. Rowan \& Littlefield.

Bourdieu, P. (1977). Cultural reproduction and social reproduction. In J. Karabel \& A. H. Halsey (Eds.), Power and ideology in education (pp. 487-511). Oxford University Press.

Bourdieu, P. (1984). Distinction: A social critique of the judgment of taste (R. Nice, Trans.). Harvard University Press.

Bourdieu, P. (1986a). The forms of capital. In J. Richardson (Ed.), Handbook of theory and research for the sociology of education (pp. 241-258). Greenwood Press.

Bourdieu, P. (1986b). The production of belief: Contribution to an economy of symbolic goods. In R. Collins, J. Curran, N. Garnham, \& P. Scannell (Eds.), Media, culture and society: A critical reader (pp. 131-163). SAGE.

Bourdieu, P. (1990). The logic of practice. Stanford University Press.

Bourdieu, P. (1991). Language and symbolic power. Harvard University Press.

Brantlinger, E. (2003). Dividing classes: How the middle class negotiates and rationalizes school advantage. Routledge.

Cao, L. L. (1997). Dreams and dilemmas: Chinese female students' experiences of overseas education in the United States [Unpublished doctoral dissertation]. Teachers College, Columbia University.

Cho, J., \& Yu, H. (2015). Roles of university support for international students in the United States: Analysis of a systematic model of university identification, university support, and psychological well-being. Journal of Studies in International Education, 19(1), 11-27. https://doi.org/10.1177/1028315314533606 
Davies, S., \& Rizk, J. (2018). The three generations of cultural capital research: A narrative review. Review of Educational Research, 88(3), 331-365. https://doi.org/10.3102/0034654317748423

Dika, S. L., \& Singh, K. (2002). Applications of social capital in educational literature: A critical synthesis. Review of Educational Research, 72(1), 3160. https://doi.org/10.3102/00346543072001031

English, F. \& Bolton, C. (Eds.). (2016). Bourdieu for educators. SAGE.

Gay, G. (2010). Culturally responsive teaching (2nd ed.). Teachers College Press.

Ge, L., Brown, D., \& Durst, D. (2019). Chinese international students' experiences in a Canadian university. Journal of International Students, 9(2), $582-612$.

Glass, C. R., \& Gesing, P. (2018). The development of social capital through international students' involvement in campus organizations. Journal of International Students, 8(3), 1274-1292.

Gold, S. J. (2016). International students in the United States. Society, 53(5), 523530 .

Habu, T. (2000). The irony of globalization: The experience of Japanese women in British higher education. Higher Education, 39(1), 43-46.

Institute of International Education. (2018). International students 2017/18. Open Doors Report on International Educational Exchange. Retrieved March 01, 2019 from https://www.iie.org/opendoors

Institute of International Education. (2019). International students by academic level and places of origin 2016/17 - 2018/19. Open Doors Report on International Educational Exchange. Retrieved March 01, 2019 from https://www.iie.org/opendoors

Kuo, Y. H. (2011). Language challenges faced by international graduate students in the United States. Journal of International Students, 1(2), 38-42.

Lareau, A. (2003). Unequal childhoods: Class, race, and family life. University of California Press.

Lareau, A., \& Horvat, E. M. (1999). Moments of social inclusion and exclusion: Race, class, and cultural capital in family-school relationships. Sociology of Education, 72(1), 37-53.

Lee, J. J., \& Rice, C. (2007). Welcome to America? International student perceptions of discrimination. Higher Education, 53(3), 381-409. https://doi.org/10.1007/s10734-005-4508-3

Levitt, H. M., Motulsky, S. L., Wertz, F. J., Morrow, S. L., \& Ponterotto, J. G. (2017). Recommendations for designing and reviewing qualitative research in psychology: Promoting methodological integrity. Qualitative Psychology, $4(1), 2-22$.

Li, J. (2012). Cultural foundations of learning: East and west. Cambridge University Press.

Lin, S. Y., \& Scherz, S. D. (2014). Challenges facing Asian international graduate students in the US: Pedagogical considerations in higher education. Journal of International Students, 4(1), 16-33.

Lincoln, Y. S., \& Guba, E. (1985). Naturalistic inquiry. SAGE. 
Liu, D., \& Brown, B. B. (2014). Self-disclosure on social networking sites, positive feedback, and social capital among Chinese college students. Computers in Human Behavior, 38, 213-219.

MacIntyre, P. D., \& Gardner, R. C. (1989). Anxiety and second language learning: Toward a theoretical clarification. Language Learning, 39(2), 251-275.

Marginson, S. (2014). Student self-formation in international education. Journal of Studies in International Education, 18(1), 6-22.

Marshall, C., \& Rossman, G. B. (2016). Designing qualitative research (6th ed.). SAGE.

National Association of Foreign Student Advisers. (2019). Economic value statistics. $\quad$ https://www.nafsa.org/policy-and-advocacy/policyresources/nafsa-international-student-economic-value-tool-v2\#main-content

Portes, A. (1998). Social capital: Its origins and applications in modern sociology. Annual Review of Sociology, 24, 1-24.

Portes, A. (2014). Downsides of social capital. Proceedings of the National Academy of Sciences of the United States of America, 111(52), 18407-18408.

Saldaña, J. (2009). The coding manual for qualitative researchers. SAGE.

Sheng, X. (2012). Cultural capital and gender differences in parental involvement in children's schooling and higher education choice in China. Gender and Education, 24(2), 131-146.

Stanton-Salazar, R. D. (1997). A social capital framework for understanding the socialization of racial minority children and youths. Harvard Educational Review, 67(1), 1-40.

Strayhorn, T. L. (2012). College students' sense of belonging: A key to educational success for all students. Routledge.

Tran, L. T. (2016). Mobility as 'becoming': A Bourdieuian analysis of the factors shaping international student mobility. British Journal of Sociology of Education, $37(8)$,

$1268-1289$. https://doi.org/10.1080/01425692.2015.1044070

Warikoo, N., \& Carter, P. (2009). Cultural explanations for racial and ethnic stratification in academic achievement: A call for a new and improved theory. Review of Educational Research, 79(1), 366-394.

Yin, R. K. (2017). Case study research and applications: Design and methods. SAGE.

Zhang-Wu, Q. (2018). Chinese international students' experiences in American higher education institutes: A critical review of the literature. Journal of International Students, 8(2), 1173-1197

XINXIN WANG, MPP, is a PhD candidate in the strand of Cultural Studies and Literacies at the School of Education, the University of North Carolina at Chapel Hill. Her research focuses on educational policy analysis, including areas of international and comparative education, higher education, critical multicultural education, and educational policies evaluation. Email: xxcheer@live.unc.edu 
REBEKAH FREED, MA, is a PhD student in the Learning Sciences and Psychological Sciences program at UNC-Chapel Hill. Her current research interests include how students self regulate while learning about difficult topics. Email: rfreed@live.unc.edu 